niences bound to this technique.

Method: We performed a prospective survey from 01 February 1999 to 31 January 2000. All patients included were of either sex that had sustained serious burns for which the local treatment was done under general anesthesia using kétamine, $2 \mathrm{mg} / \mathrm{kg}$, IV with spontaneous ventilation.

Results: A total of 60 patients, 33 female and 27 male, were included. The age ranged between 8 months and 60 years with $35 \%$ between of 0 to 5 years of age. The level of pain experienced was assessed for each of the patients: $15 \%$ signalled small pains; $30 \%$, strong pains; and 55\%, "atrocious" pains. $63.3 \%$ were very relieved of their douleurs; $6.7 \%$ experienced tiredness, even though the analgesia was sufficient; $30 \%$ could not express their point of view because they didn't have access to the language (preschool age). Undesirable effects associated with the technique occurred in 12 neurologically troubled patients: leses (delirium and hallucination) were experienced by $10 \%$, follow-up of qualms and vomiting by $6.7 \%$, and dizziness by $3.3 \%$.

Conclusion: This technique deserves to be known and mastered by all anesthetists. This work permitted us to appreciate the level of pain experienced by burned patients at CHU Tokoin, and to deal it with means that we arrange. In a general way, this technique of analgesia increases the comfort of the patient, reduces the stress, gains time for taking care of it at the time of provision of the local cares, augments the acceptability of the treatment by the patient and the renewal of confidence of the patient for the personnel providing the care.

Key words: analgesia; anaesthesia; burns; care; comfort; effects; ketamine; treatment

Prebosp Disast Med 2001;16(2):s93.

\section{Experiences Using a Simulation Model for Training of Hospital Management in Major Accidents and Disasters}

Professor Sten Lennquist

Linköping University, Centre for Teaching and Research in Disaster Medicine, University Hospital, Linköping, SWEDEN

Introduction: There are many well-established methods for training of prehospital management and performance in major accidents and disasters. However, very few methods have been developed for the training of the work in the hospital. There is a demand for such training, because of the increasing imbalance between available resources and need of resources created by an increasing need of medical care parallel to efforts to reduce costs.

Bringing consultants into the hospital is expensive and interferes with normal hospital activities; thus, it must be restricted. With plain computer simulations, it is difficult to illustrate a realistic situation to motivate the staff sufficiently.

Methods: Based on a previously demonstrated method for prehospital simulation with movable magnetic symbols and markers on white-board screens, a model has been developed for hospital management, in which all staff in com- mand and coordinating positions can be trained interactively. Each training session gives a measurable result expressed in avoidable deaths and avoidable complication of different degrees. This method now has been used in exercises for 1,800 participants, 1,400 on national level, and 400 on international level organised by the WHO, $\mathrm{EU}$, and countries in different parts of the world.

Results: The sessions were evaluated with regard to their accuracy and value, and when the same participants repeated the session, the results were compared. The value generally was very high $(4.8 \pm 0.4$ and $4.4 \pm 0.6$, respectively, on a scale 1.0-5.0). When repeated training sessions were performed a significant improvement of outcome was registered.

Conclusion: The model so far has shown to be both accurate and valuable, and can be recommended for use for this purpose.

Key words: command; coordination; disaster; hospital; management; model; multicasualty incidents; simulation; training

E-mail: Sten.Lennquist@lio.se Prehosp Disast Med 2001;16(2):s93.

\section{Work-related Burns: Eight Year Retrospective Study Bouelmik Mnarin; Elmi Hassen; Meherzi B; Messadi A}

Service de Reanimation de Brule et De Ghirurgie Burn Department, Hospital Aziza Othmana, TUNIS

A retrospective, multifactoral, epidemiological study of patients with burns injuries that occurred during work, who were admitted to the intensive care Burn Department in Aziza Othmana's Hospital, during a eight-year period from January 1992 to December 1999, was undertaken. A total of 316 patients with work-related burns were admitted. The mean of the patients' ages was 32 years. Males accounted for $91.5 \%$ of these admissions.

The mean value for the percentage of body surface area burned was $35 \%$. Electrical burns were found in 116 cases $(36.7 \%)$, chemical burn in 11 cases $(3.5 \%)$, and thermal burn in 189 patients $(59.8 \%)$. The mean time in the hospital was 16 days and 41 patients $(13.0 \%)$ died as a result of their injuries.

Work-related burns are frequent and represent $26 \%$ of all admissions and have a high mortality rate (12\%). More effort must be done to improve prevention of burn injuries during work.

Key words: burns, work-related; chemicals; electrical; mortality; thermal

\section{The United States Public Health Service Noble Training Center \\ K. Joanne McGlown, RN, MHHA, CHE, PhD}

Jacksonville State University, Alabama, USA

The United States Public Health Service (USPHS) Office of Emergency Preparedness (OEP) is converting what was the 100-bed Noble Army Hospital, into the USPHS Noble Training Center (NTC). This facility, located on 20- 
acres of the former Ft. McClellan (Alabama), will be the only hospital facility in the U.S. devoted entirely to multidisciplinary medical training, applied research and beta testing, injury treatment, protection of health care personnel and facility protection for Weapons of Mass Destruction (WMD) incidents. It is co-located at Ft. McClellan with the Department of Justice's Center for Domestic Preparedness (CDP) where training courses, including live agent training, are provided for first responders and emergency management personnel. The NTC will provide a mock hospital environment where learning will be accomplished through training, drills and experimentation without disrupting patient care. The NTC will also serve as a beta test sight for new initiatives in facility protection, communications, HVAC operation and decontamination systems. The center will have two fixed mass casualty decontamination lanes and one mobile decontamination system to provide options for hospital implementation. Emphasis is placed on dual use of existing space. Training courses will be provided expense-free for all U.S. attendees. Courses to be taught will include: Hospital Provider Course (multidisciplinary team of hospital leadership), Emergency Medical Services Course, WMD Mass Casualty Course for EMT's, and the Pharmacists Course for the National Pharmaceutical Stockpile Program. With the availability of a training village, complete with multistory buildings, highly realistic, real-time field disaster drills will be designed for prehospital personnel. Mock casualties, after appropriate decontamination and medical care, will be evacuated to the NTC using modular civilian ambulances, where they will be met by the Hospital Provider Course students, allowing both groups to understand and practice the complete chain of evacuation and coordination.

Key Words: hospital; prehospital; public health; training E-mail: kjmcglown@wwisp.com

Prehosp Disast Med 2001;16(2):s94. 